\title{
Fraser Syndrome
}

National Cancer Institute

\section{Source}

National Cancer Institute. Fraser Syndrome. NCI Thesaurus. Code C118436.

A rare, autosomal recessive inherited disorder caused by mutations in the FRAS1, FREM2, or GRIP1 genes. It is characterized by the presence of cryptophthalmos, cutaneous syndactyly, and genitourinary abnormalities. 